\title{
Development and Performance Evaluation of a Low Cost Multi-Purpose Tool Carrier with Matching Tillage Tools
}

\author{
Nandni Thakur and Manisha Jagadale*
}

Central Institute of Agricultural Engineering, Bhopal (M.P), 462038, India

*Corresponding author

\section{Keywords}

MPTC, Tillage,

Field efficiency

\section{Article Info}

Accepted:

16 August 2018

Available Online:

10 September 2018

\section{A B S T R A C T}

Small landholders cannot afford to buy tractor as well as maintenance of bullocks has become very costly particularly when they are not in use. By using the multipurpose power unit the small and medium farmers can avoid the year round maintenance of bullocks and also the high investment in tractors. The multipurpose tillage tool carrier (MPTC) developed and tested along with ploughing (primary tillage) and leveling (secondary tillage). The performance evaluation of tillage tools i.e. Mouldboard plough and horizontal blade were done with MPTC with the help of $5 \mathrm{hp}(3.7 \mathrm{~kW})$ power unit. The experiments were conducted with three moisture content $6.6,12$ and $20 \% \mathrm{db}$. The tool carrier designed for attachment of plough and horizontal blade is found suitable for tillage operation due to its simple design. There was ability to adjust width of cut, depth of cut, row spacing with little adjustment. The developed MPTC has proper matching ability with the selected 3.7 $\mathrm{kW}$ power unit. The developed unit evaluated for field efficiency $(\%)$, unit draft $\left(\mathrm{N} / \mathrm{cm}^{2}\right)$, power requirement $(\mathrm{kW})$, energy requirement $(\mathrm{kWh} / \mathrm{ha})$, performance index $(\%)$, fuel consumption (lit/ha), field capacity $(\mathrm{ha} / \mathrm{h})$, soil pulverization $(\mathrm{mm})$ and cone index $(\mathrm{kPa})$ at different moisture content $(6.6 \%, 12 \%$ and $20 \%)$. The utilization of power during the operation of MPTC with m.b. plough and blade were 0.8 and $0.5 \mathrm{~kW}$ respectively. The average field capacity was $0.20,0.21 \mathrm{ha} / \mathrm{h}$, field efficiency were 86.6 and $89.1 \%$ and Energy requirement and soil pulverization were $3.3,2.9 \mathrm{Kwh} / \mathrm{ha}$ and $12.1,3.3 \mathrm{~mm}$ respectively at $20 \%$ moisture content of soil with $2.5 \mathrm{~km} / \mathrm{h}$ speed. The experiment result show that m.b. plough performed satisfactory at $20 \%$ moisture content as primary tillage tool. The developed m.b. plough is a low cost implement and may be proved as very useful to the small farmers.

\section{Introduction}

Agricultural productivity is linked with the availability of farm power. Field preparations of small farms presently become difficult because of socioeconomic condition of small and marginal land holding of farmers. Small farmers can't afford large tractors because of high turning loss as well as high cost of operation. In India, $70 \%$ of the total land holdings possessed by small and marginal farmers (Nayak and Ajay 2012). Average size of a farm holding which was 1.69 ha in 198586 came down to 1.33 ha in $2000-01$ and 1.15 ha in 2010-11 (Agricultural Census Division, Ministry of Agriculture). 
In most of the Madhya Pradesh the number of bullocks are depleting at faster rate under these circumstances, the walking type twowheel drive power unit may become the most promising power source for agricultural operations at the level of small and medium farmers. Walking type power tillers introduced in Indian agriculture in early sixties that too only for preparation of seedbed for paddy cultivation.

In general, the available power units are usually developed for a specific kind of work. Small and marginal farmer cannot purchase different machines for different operations. Farmers have a long felt need for such an implement that is lightweight, low cost, durable and labor saving.

The only solution to the problem is the development of multipurpose power unit and it's matching implements. One of the major factor affecting crop yield is timeliness of operation. The fabrication of low cost implement is possible only when a common frame is developed for different attachments.

Development of small multipurpose power unit is quite affordable and useful to farmers. It can be fabricated and repaired by village artisans. The structure of power unit is simple; this makes the operation, maintenance and repairs easy. The row to row distance could be adjusted according to crop requirements in all operations. Usually the operator may repairs at field without any drudgery. It offers several advantages like timeliness in farm operation, quality, precision of work, increased work rate, efficient utilization of machine power, reduction in human drudgery and allow for year round use due to its versatility.

Power tiller is a popular power source in Asian countries where rice is produced as a main cereal crop. In Madhya Pradesh, it is not used in larger extent as in most part of the state soil is hard, heavy and sticky. Therefore, it has become necessary to develop the multipurpose frame, on which both the tillage machinery like mould board plough and secondary tillage implement can be attached.

\section{Design consideration}

\section{Selection of materials}

Selection of proper materials for manufacturing various components of multipurpose tool carrier with tillage tools is very important. The farm machinery has to work under severe hazardous and heterogeneous environmental conditions. It should be adequately strong, stiff. The machine elements should be readily shaped, welded and easily machineable.

\section{Design of frame}

Tillage tools are attached to the tines; these are mounted on the main tool carrier frame which was hitched to the power unit frame. Frame provide different adjustment for soil cutting tools, it provides different width and depth adjustment according to tillage and inter culture operation requirement (Table 1). A multipurpose tool carrier was developed as an attachment to the power tiller. The general requirements of the machine, the conceptual design, fabrication methods and procedure adopted for field trials are presented below.

The frame was made out of hollow square section of $40 \mathrm{~mm}$ sides. This square bar helps in mounting of m.b. plough and secondary tillage tools at different row spacing, working height (Fig. 1).

A hollow square made out of channel section with telescopic action attached to the frame which facilitates the height adjustment of the depth cum transport wheel on center of the unit. 


\section{Design of mould board plough}

The implement consists of a share, mould board, landside, depth gauge wheel and frame (Fig. 2). The share is made from medium or high carbon steel and hardened to resist wear during operation. The mould board that inverts the soil is made of mild steel. The gauge wheel is used to control the depth of operation. It has convenient handles for easy operation. For operation, the plough is move in the soil with the help of a power unit. Share of the plough penetrates into the soil and makes a cut below the soil surface. Mould board lifts, pulverizes and inverts the furrow slice.

\section{Land side}

$\mathrm{L}=\frac{1}{2} \times \frac{b \cos \emptyset}{\sin \propto \cos (\emptyset+\propto)}$

$=\frac{1}{2} \times \frac{b \cos 20}{\sin 15 \cos (20+15)}=170 \mathrm{~mm}$

$\mathrm{L}=$ length of land side from the point of share to hell of landside $(\mathrm{mm}), \mathrm{b}=$ width of landside $(\mathrm{mm}), \varnothing=$ angle of soil granular friction $\left({ }^{\circ}\right), \propto$ $=$ inflation of pull with vertical plane, $\mathrm{L}=170$ $\mathrm{mm}, \mathrm{B}=60 \mathrm{~mm}$, Thickness $(\mathrm{t})=15 \mathrm{~mm}$

The implement, consists of one or more blades attached to the beam or frame, used for shallow working in the soil (Fig. 2). It is used to prepare seedbed mostly in clayey soils. It works like a sweep, which slices the top surface of the soil with less inversion of soil.

This is done to achieve a desired granular soil structure for a seed bed and to allow rapid infiltration and good retention of moisture, to provide adequate air exchange capacity within the soil and to minimize resistance to root penetration and shoot growth. Local plough (Hat) and blade harrow (Bakhar) are traditional implements used for loosening of soil. It cuts a thin slice of soil and removes the weeds. These are simplest tools designed to break the top soil and multi-passes are carried out to prepare seedbed. The shape of the blade is slightly concave, for increased inversion and penetration. This implement has multiple utilities and can also be used for exposing potato tubers and digging out ground nut vines from the soil. Once its soil-working components etc. worn out it can be reshaped and fitted again to improve its performance.

\section{Size of cutting blade (Horizontal blade)}

\section{Specifications}

Working width (mm): $720 \mathrm{~mm}$

Cutting width of blade (mm): $240 \mathrm{~mm}$

Shape of blade: concave

Power requirement: self-propelled power unit (5 hp)

\section{Testing}

Cultivation of the different crops requires different implements. The traditional implements have no adjustment for row to row distance and not provided with additional part for attachment of other implement, thus it is used for fixed type operation. Also, in field condition, the implement parts break at the joints and require repair time. Farmers have a long felt need for such an implement that is light weight, low cost, durable and labour saving. A small power drawn, multipurpose tool carrier was designed which could be used as a plowing and secondary tillage operation, inter culturing and leveling with adjustable row to row spacing. Performance of the multipurpose tool carrier was evaluated for primary and secondary tillage operation.

The instruments used for measuring different parameters were; digital dynamometer, torque meter, fuel consumption measuring device, sieve analysis, cone penetrometer and the corresponding parameters were $\mathrm{db}$ pull, 
Torque on axel, specific fuel consumption and power requirement, mean mass diameter of soil sample, compactness of soil at different depth.

The theoretical field capacity obtained if implement were performing its function $100 \%$ of the time at the rated speed and always covering $100 \%$ of its rated width. Field capacity was calculated by following expression:

Theoretical field capacity $(\mathrm{ha} / \mathrm{h})=$ widthof cuttingtool $(\mathrm{m}) \times$ Speed of operation $\left(\frac{\mathrm{km}}{\mathrm{h}}\right)$ 10

Actual field capacity $(\mathrm{h} / \mathrm{h})=$ Widthoffieldcoverage (m) XLengthoffieldcoverage (m) Timeforcoveringtotalarea $(\mathrm{h}) \times 10000$

Performance index PI = $\frac{1}{\operatorname{MMD}(\mathrm{mm}) \times D_{\mathrm{u}}\left(\frac{\mathrm{kg}_{2}}{\mathrm{~cm}}\right)} \times 100$

$\mathrm{PI}=$ Performance index in $\%, \mathrm{D}_{\mathrm{u}}=$ Unit draft in $\mathrm{kgf}$ per $\mathrm{cm}^{2}, \mathrm{MMD}=$ Mean mass diameter $(\mathrm{mm})$

Unit draft = --------------- $\mathrm{kg} / \mathrm{cm}^{2}$

Cross section of area of furrow

\section{Power requirement}

Power is the rate of doing work. Common units are the kilowatt in the SI system.

Power requirement $(\mathrm{kW})=$ $\operatorname{Draft}(\mathrm{kN}) \times \frac{\text { speed } \mathrm{km} / \mathrm{h}}{3.6}$

Energy requirement $(\mathrm{kWh} / \mathrm{ha})=$ power requirement (kW)

theoretical field capacity(ha/h)

Fuel consumption (1/ha) $=\frac{\text { Fuel consuption (1) }}{\text { Area covered (ha) }}$

\section{Results and Discussion}

The experiments were conducted to test two types of tools under actual field condition.

\section{Performance of multipurpose tillage tool carrier}

The multipurpose tool carrier was used for different implements like ploughing, harrowing and sowing etc. The multipurpose tool carrier was developed as an attachment to the power tiller by simple nuts bolts adjustment. The MPTC can easily be coupled with different matching implements. Tests were conducted to evaluate the performance of the multipurpose tool carrier with m.b plough and horizontal blade (3 tynes) in field conditions. The adjustments of the multipurpose tool carrier with their matching tools are presented in Figure 4 and 5.

The developed unit evaluated for field efficiency $(\%)$, unit draft $\left(\mathrm{N} / \mathrm{cm}^{2}\right)$, power requirement $(\mathrm{kW})$, energy requirement $(\mathrm{kWh} / \mathrm{ha})$, performance index (\%), fuel consumption (lit/ha), field capacity (ha/h), soil pulverization $(\mathrm{mm})$ and cone index $(\mathrm{kPa})$ at different moisture content $(6.6 \%, 12 \%$ and $20 \%$ ) for m.b plough and horizontal blades (3 tynes). From evaluation it was observed that performance for each parameter was significant $(<0.01)$ at $20 \%$. The values of each parameter are shown in below figure 3 . The important components of tool carrier are common frame and tynes that can be used for mounting of different tillage tools. Because of this farmers can save the expenditure of buying different implements.

The developed tool carrier is found suitable due to its simple design. It has provision for changing width of cut, depth of cutting and row spacing at an ease the tool carrier with the size of $(1000 \times 315 \mathrm{~mm})$ is found right size and good matching for prime mover of $3.7 \mathrm{~kW}$ (Table 2 and 3 ). 
Table.1 Specification of multi-purpose tool carrier with different attachments

\begin{tabular}{|c|c|c|c|}
\hline $\begin{array}{l}\text { S. } \\
\text { no. }\end{array}$ & Parts & Material used & Specification \\
\hline 1. & Main frame & MS square section & $1000 \times 315 \mathrm{~mm}$ \\
\hline 2. & $\begin{array}{ll}\text { Tyne } & \\
\text { a) } & \mathrm{t} 1 \\
\text { b) } & \mathrm{t} 2\end{array}$ & $\begin{array}{l}\text { MS square rod } \\
\text { Heavy duty cast iron }\end{array}$ & $\begin{array}{l}20 \times 20 \mathrm{~mm} \text { diameter } \\
600 \mathrm{~mm} \text { (adjustable) } \\
100 \mathrm{~mm}\end{array}$ \\
\hline 3. & Frame clamp & $\begin{array}{l}\text { MS square section, mild } \\
\text { steel }\end{array}$ & $100 \times 40 \mathrm{~mm}$ \\
\hline 4. & Tyne clamp & Mild steel & $100 \times 25 \mathrm{~mm}$ \\
\hline 5. & Tools & Heavy duty cast iron & $230 \times 100 \mathrm{~mm}$ \\
\hline 6. & $\begin{array}{l}\text { Depth control } \\
\text { wheel }\end{array}$ & $\begin{array}{l}\text { Mild steel with solid rubber } \\
\text { cover }\end{array}$ & $300 \times 400 \mathrm{~mm}$ \\
\hline
\end{tabular}

Table.2 Specification of frame

\begin{tabular}{|l|}
\hline Type of frame \\
\hline Weight of frame \\
\hline Bolt size \\
\hline No. of tyne \\
\hline Tyne adjustment \\
\hline Tyne adjustment (one tyne in frame) \\
\hline Dimension of frame \\
\hline
\end{tabular}

Telescopic
$15 \mathrm{~kg}$
$10 \mathrm{~mm}$
3
Zig-zag type (shown Plate1)
$300 \mathrm{~mm}$
$1000 \times 315 \mathrm{~mm}$

Table.3 Specifications of designed mould board plough (Ref. fig. 3)

\begin{tabular}{|l|l|}
\hline Shear lift angle $y^{\circ}$ & $35^{\circ}$ \\
\hline Shear side angle $\rho$ & $45^{\circ}$ \\
\hline Mould board lift angle $\varnothing$ & $60^{\circ}$ \\
\hline Mould board side angle $\partial$ & $40^{\circ}$ \\
\hline Vertical suction v & $20 \mathrm{~mm}$ \\
\hline cutting width b & $220 \mathrm{~mm}$ \\
\hline Height h & $310 \mathrm{~mm}$ \\
\hline Length l & $170 \mathrm{~mm}$ \\
\hline Share rack angle & $20^{\circ}$ \\
\hline Total width & $240 \mathrm{~mm}$ \\
\hline
\end{tabular}


Fig.1 Orthogonal view of multipurpose tillage tools carrier

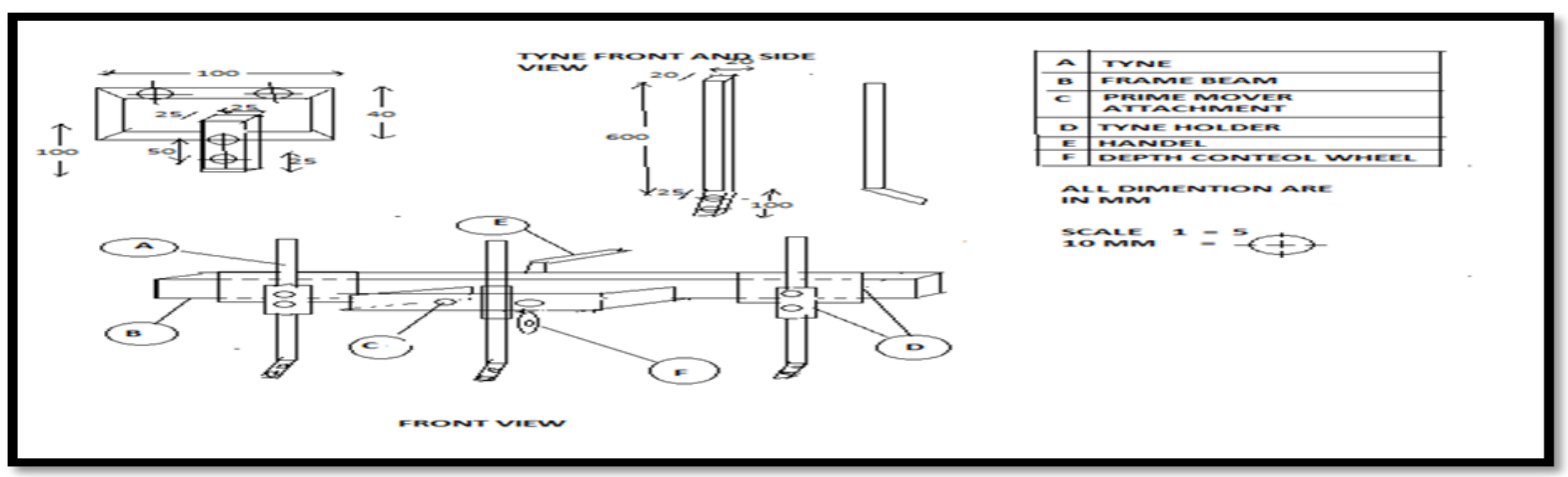

Fig.2 Orthogonal diagrams of horizontal blade

Fig.3 Orthogonal diagram of m.b.plough

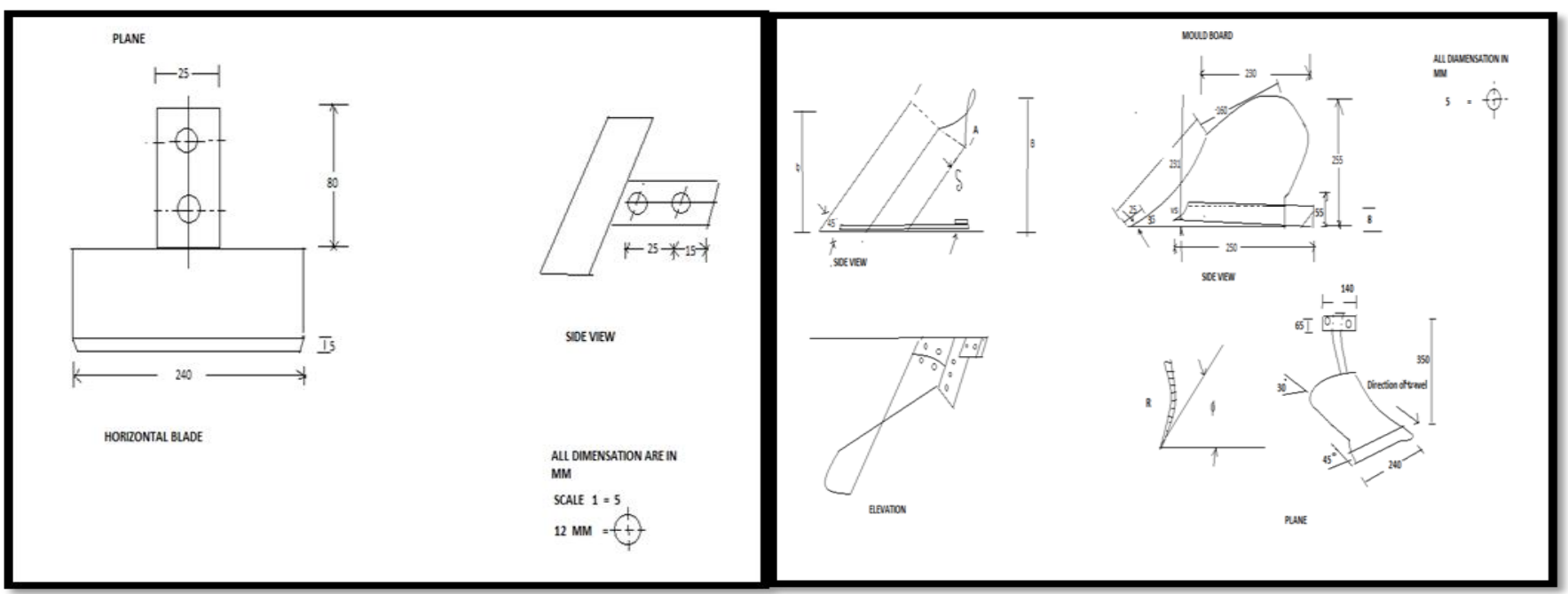

Fig.4 Frame attachment with blade

Fig.5 Frame attachment with plough
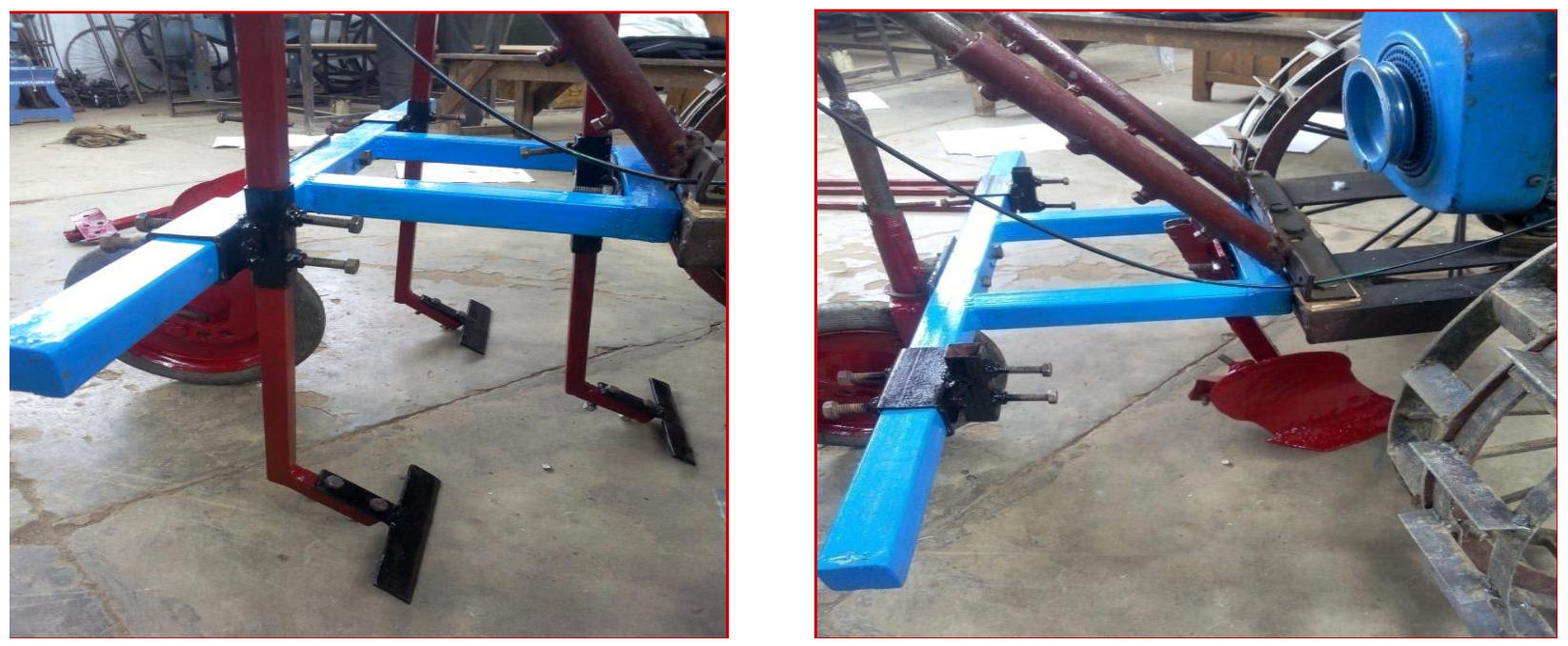


\section{Performance of multipurpose tillage tool carrier}

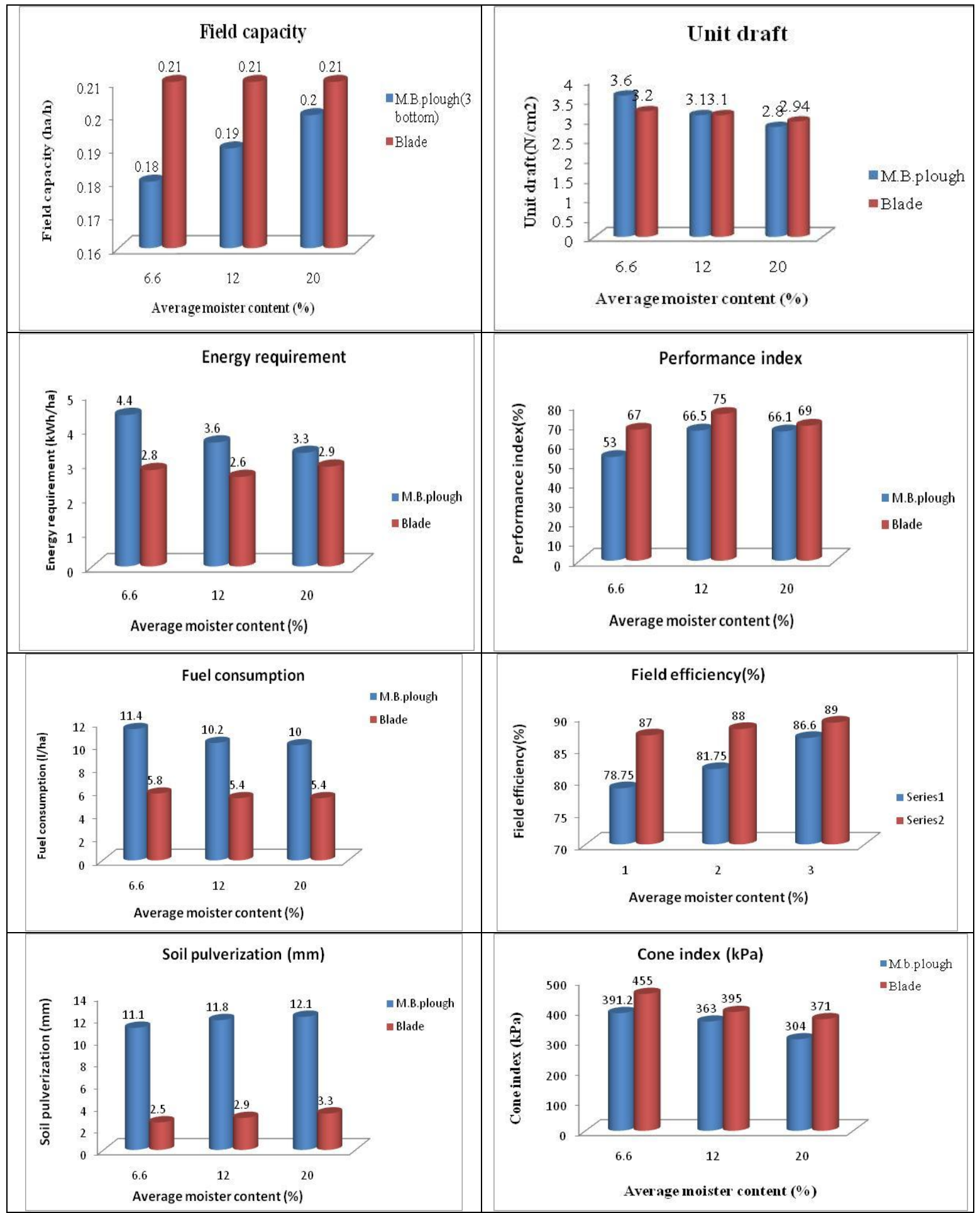

Tool carrier found suitable for year round use and less $t$ time required for depth adjustments. The problem of clogging was solved by using zig-zag tynes. The provision is made to accommodate 1-3 Tyne as required by providing telescopic frame. 
The m.b. plough was tested as primary tillage tools and its maximum field capacity was 0.2 ha/h with efficiency of $74 \%$. The fabricated plough under good soil condition can achieve the depth of $190 \mathrm{~mm}$ and width of cut 223 $\mathrm{mm}$. The power requirement for operation of single plough is only $0.8 \mathrm{~kW}$ and unit draft calculated was $3.6 \mathrm{~N} / \mathrm{cm}^{2}$. Thus 3 bottom plough can easily be operated by selfpropelled unit having power of $3.7 \mathrm{~kW}$ which consumed an average of $11.4 \mathrm{l} / \mathrm{ha}$. This also increased the vertical suction from $3 \mathrm{~mm}$ to 5 $\mathrm{mm}$.

There exists significant variation in power requirement, bulk density, energy requirement and soil pulverization under different m.c. of soil and different shape of tools. Interaction effect of all tillage tools (selected plough, horizontal blade) on cone index, field efficiency, fuel consumption and performance index at three selected m.c. of soil were significant at $1 \%$.

The horizontal blade with $240 \mathrm{~mm}$ with found satisfactory for leveling of the field however it perform as secondary tillage is not recommendable.

Therefore it is concluded that developed low cost tool carrier having common frame and tynes is an effective linkage to connect tools for easy attachment. M.b. plough performed satisfactory as primary tillage tool and horizontal blade can also be used effectively for leveling.

\section{References}

Ahmadi H and Mollazade K. 2009. Effect of plowing depth and soil moisture content on reduced secondary tillage. Agricultural Engineering International, The CIGR E Journal, manuscript MES, 1195.
Ailkins SHM and Afuakwa JJ. 2012. Effect of four different tillage practices on soil physical properties under cowpea. Agriculture and Biology Journal of North America, 3(1):17-24.

Ali Hashemi, Desa Ahmad, Jamarei Othman and Shamsuddin Sulaima. 2012. Development and Testing of a New Tillage Apparatus. Journal of Agricultural Science; Vol. 4, No. 7, ISSN 1916-9752

Angela Hiuhu, AyubNjorogeGitau and Duncan OnyangoMbuge.2015. Optimization of the Angle of Frog in Mouldboard Tillage Operations in Sandy Clay Soil, Open Journal of Optimization, 2015, 4, 131-140.

Askari M and Khalifahamzehghasem S. 2013. Draft force input for primary and secondary tillage implements in a clay loam soil. World Applied Sciences Journal, 21(12): 1789-1794.

Bacon CA. 1918. Plough Bottom Design. Trans. ASAE, 12(1): 26-42.

Bishwas HS, Ingle GS. And Ojha TP. 1993. Performance evaluation and optimization of straight blades for shallow tillage and weeding on black soils. AMA 22 (1): 45-48.

Chandan K and Kushwaha RL.2002.Soil force on deep tillage tolls. CSAE/SCGR Secretary, PO Box316, Mansonville, QC J0E 1X0.Tel/FAX 450-292-3049.

Chandegara VK. 2009. Development of Low Cost, Bullock Drawn, Multi- Purpose Implement for Sandy Loam Soil. VOL.40 NO.4 2009. Agricultural Mechanization in Asia, Africa, and Latin America

CIAE, 1980.Bakhar blade and patella harrow. pp. 26-28 in: Annual report 1976-79, Central Institute of Agricultural Engineering (CIAE), Bhopal, India

Collins EV. 1963. Factors influencing the draft of plough. Trans. ASAE, 44:3947. 
Dhakane AD, Turbatmath PA and Pandey V. 2010. The field performance evaluation of tractor operated combination tillage implement International Journal of Agricultural Engineering, 3 (1): 138143.

Gard, Devnani 1983. Studies on multipurpose tool frame to reduce drudgery during Kharf, Rabi and summer season.

Kumar A. and Varshney B.P. 2003 Development and evaluation of power tiller operated matching implement. Agricultural Engineering. Today, Vol. 27 (5-6): 18-26.

Nayak VK and Verma A. 2012. Performance evaluation of animal drawn multipurpose tool carrier for tillage and Biasi operations. International Journal of Agricultural Engineering. (5):254 259.

Nichols ML, Reed IF and Reaves CA. 1958. Soil Reaction to Plough Design. Agricultural Engineering. 39(6):336324.

Owende PMO and Ward SM. 1999.Reaction forces of lightweight mouldboard ploughs at slow speeds of tillage in Nitosol. Department of Agricultural and Food Engineering, University College Dublin, Earlsfort Terrace, Ireland Soil and Tillage Research. 49: 313-323.

Savani and JB. 1987. Studies on design and size of bullock drawn multi- purpose pipe frame implement in context with improvement in design and ield performance. An unpublished M. Tech thesis sub- mitted to G.A.U. Anand.

\section{How to cite this article:}

Nandni Thakur and Manisha Jagadale. 2018. Development and Performance Evaluation of a Low Cost Multi-Purpose Tool Carrier with Matching Tillage Tools. Int.J.Curr.Microbiol.App.Sci. 7(09): 2151-2159. doi: https://doi.org/10.20546/ijcmas.2018.709.264 